\title{
A retrospective study of the incidence and predisposing factors of third- and fourth-degree perineal tears
}

\author{
Deama S. Al Ghamdi, MD.
}

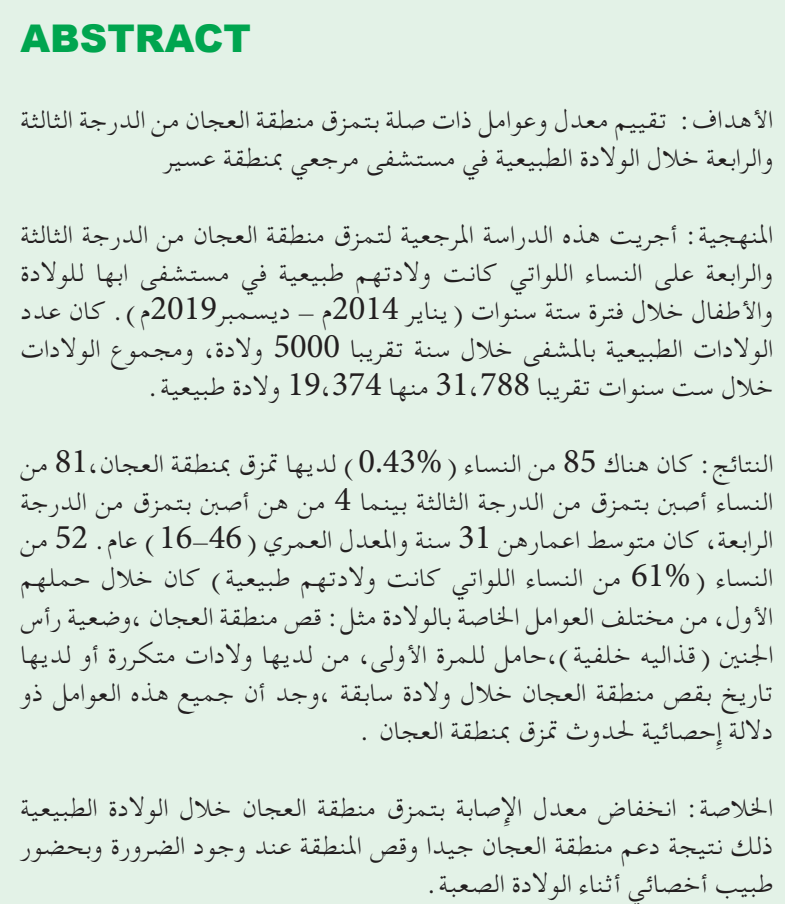

Objectives: To evaluate the rates of third- and fourthdegree tears and related predisposing factors for the tears in singleton vaginal deliveries.

Methods: This was a retrospective study of third- and fourth-degree perineal tears in all women who underwent vaginal delivery in a tertiary hospital in Assir region between January 2014 and December 2019. There are approximately 5000 deliveries per year at the Abha Maternity and Children Hospital. The total number of deliveries during the study period was 31,788 , of which 19,374 were delivered vaginally.

Results: A total of 85 women $(0.43 \%$ of all vaginal deliveries) had third-degree $(\mathrm{n}=81)$ or fourth-degree $(n=4)$ perineal tears. The mean age of the women was 31 years (range: $16-46$ years). Fifty-two of the 85 women $(61 \%)$ were primiparous. Of the various obstetric parameters, episiotomy, occipitoposterior presentation, primigravida, multipara, and a previous episiotomy were found to be significant predisposing factors to third- and fourth-degree tears in our patients.

Conclusion: The low incidence of obstetric anal sphincter injuries in this study is likely the result of proactive manual protection of the perineum, valid indications for episiotomy, and attendance of senior staff members at all difficult deliveries.

Keywords: perineal, third-degree tear, fourth-degree tear, OASIS

Saudi Med J 2020; Vol. 41 (11): 1241-1244 doi: $10.15537 /$ smj.2020.11.25498

From the Department of Obstetrics and Gynecology, Abha Maternity and Children Hospital, Abha, Kingdom of Saudi Arabia.

Received 27th August 2020. Accepted 15th October 2020.

Address correspondence and reprint request to: Dr. Deama S. Al Ghamdi, Department of Obstetrics and Gynecology, Abha Maternity and Children Hospital, Abha, Kingdom of Saudi Arabia. E-mail:dr.deema11@hotmail.com

ORCID ID: https://orcid.org/0000-0002-1347-4737

$\mathrm{O}$ bstetric anal sphincter injuries (OASIS) occur spontaneously with vaginal delivery or as an extension to episiotomy. The injuries range from first to fourth degree depending on the anatomical structure involved. The most recognized classification of OASIS is the one adopted by the Royal College of Obstetricians and Gynecologists (RCOG). ${ }^{1-3}$ The risk for OASIS is approxiamtely $1 \%$ of all vaginal deliveries. ${ }^{3}$ Obstetric anal sphincter injuries can have a significant impact on women by impairing their quality of life in the short and the long terms. Pain, which may lead to urinary retention and sexual dysfunction, is the most common short-term complication, while dyspareunia may result 
from long-term perineal pain. ${ }^{4}$ Anal incontinence secondary to OASIS may be the most distressing and disabling complication. ${ }^{4,5}$ Well-established risk factors for OASIS that have been recognized by the RCOG are being primiparous, induced labor, prolonged second stage of labor, shoulder dystocia, ethnicity, medial episiotomy, occipitoposterior position, vacuum extraction, and birth weight $>4 \mathrm{~kg}$. The incidence of these factors varies markedly among studies. ${ }^{6-9}$

This study aim to evaluate OASIS and related predisposing factors in singleton vaginal deliveries over 6 years at the Maternity and Children Hospital in Abha in the Assir Region of the Kingdom of Saudi Arabia.

Methods. In this retrospective study of OASIS and related predisposing factors, we used the hospital database and labor ward registry book and reviewed the patient record notes of 31,788 deliveries at our hospital over the period from January 2014 through December 2019. Approval for this study was obtained from the Local Ethics Committee in King Khalid University Research Center (HA-06-B-001).

Only women who had delivered vaginally were included in the study. Women who had i) an elective or emergency cesarean section, ii) a baby whose birth weight was $<500 \mathrm{~g}$, and iii) a preterm delivery were excluded.

Basic data obtained included age, type of delivery, duration of the second stage of labor, position of the fetal head, whether delivery was an instrumental delivery, whether labor was induced, type of episiotomy done, whether labor was precipitous, post maturity, weight of the delivered baby, position of the woman during delivery, and presence of shoulder dystocia.

Results. The total number of deliveries during the 6-year period was 31,788 (mean of 5000 deliveries per year), with 19,374 delivered vaginally and 12,201 $(38 \%)$ delivered via cesarean section. Of the remaining 19,587 records, 213 were excluded and 19,374 were included in the study according to the inclusion and exclusion criteria. The mean age of the women was 31 years (range: $16-46$ years). A total of 85 women $(0.4 \%)$ who had a vaginal delivery had third-degree $(n=81)$ or fourth degree $(n=4)$ perineal tears. All delivered in the

Disclosure. Authors have no conflict of interests, and the work was not supported or funded by any drug company. lithotomy position. Figure 1 shows the rate and type of third- and fourth-degree OASIS according to the accepted classification.

All episiotomies were mediolateral and more than $60 \%$ of them were performed on primiparas. The commonly observed predisposing factors for perineal tears were undergoing an episiotomy, persistent occipitoposterior position of the head, and being primiparous. Figure 2 shows the common predisposing factors found in this study with respect to the number of women who developed OASIS $(p<0.02)$. Other risk factors for perineal tears, such as induction of labor $(n=8 ; 9 \%)$, weight of the baby $(n=3 ; 4 \%)$, post maturity $(n=5 ; 6 \%)$, head circumference $(n=2 ; 2 \%)$, and shoulder dystocia $(n=5 ; 6 \%)$, are well-known predisposing factors for OASIS (with $p>0.25$ ).

Discussion. The overall incidence of OASIS ranges widely from $0.73 \%$ to $8 \%$ of all vaginal deliveries. ${ }^{10-13}$ Factors consistently associated with OASIS are instrumental delivery, prolonged second stage of labor, being primiparous, a fetus large for gestational age, and occipitoposterior position. ${ }^{14-18}$ The lower incidence of OASIS in our study $(0.43 \%)$ is likely a result of proactive labor management, timely episiotomy, avoidance of median episiotomy, and close observation by senior staff members in difficult cases. Manual assistance during the final part of the second stage of labor can significantly decrease in obstetric anal sphincter injuries. ${ }^{19}$

In our study, $78 \%$ of women who had undergone an episiotomy had OASIS, with the majority of the women primiparous. In our center, episiotomies are usually mediolateral. Reports conflict regarding episiotomy as a risk factor for OASIS. ${ }^{11,14,15}$ However, randomized controlled trials have failed to demonstrate a significant reduction of OASIS in women who underwent an episiotomy compared with OASIS in women who did not. ${ }^{16} \mathrm{~A}$ case-controlled study showed scared episiotomy with depth more than $16 \mathrm{~mm}$, length more than $17 \mathrm{~mm}$, incision more than $9 \mathrm{~mm}$ lateral of mid-point and angle range 30-600 are significantly associated with less risk of OASIS. ${ }^{20}$

In our study, 56 women $(66 \%)$ had a fetus in the occipitoposterior position, a well-known risk factor for OASIS in several studies. ${ }^{14,21,22}$ In addition, 52 women (61\%) who were primigravida, considered a potential risk factor for OASIS, developed OASIS. A similar rate was observed in many retrospective and prospective studies. ${ }^{23}$

Multiple deliveries (38\%), a previous episiotomy $(35 \%)$, and instrumental delivery $(24 \%)$ are well- 


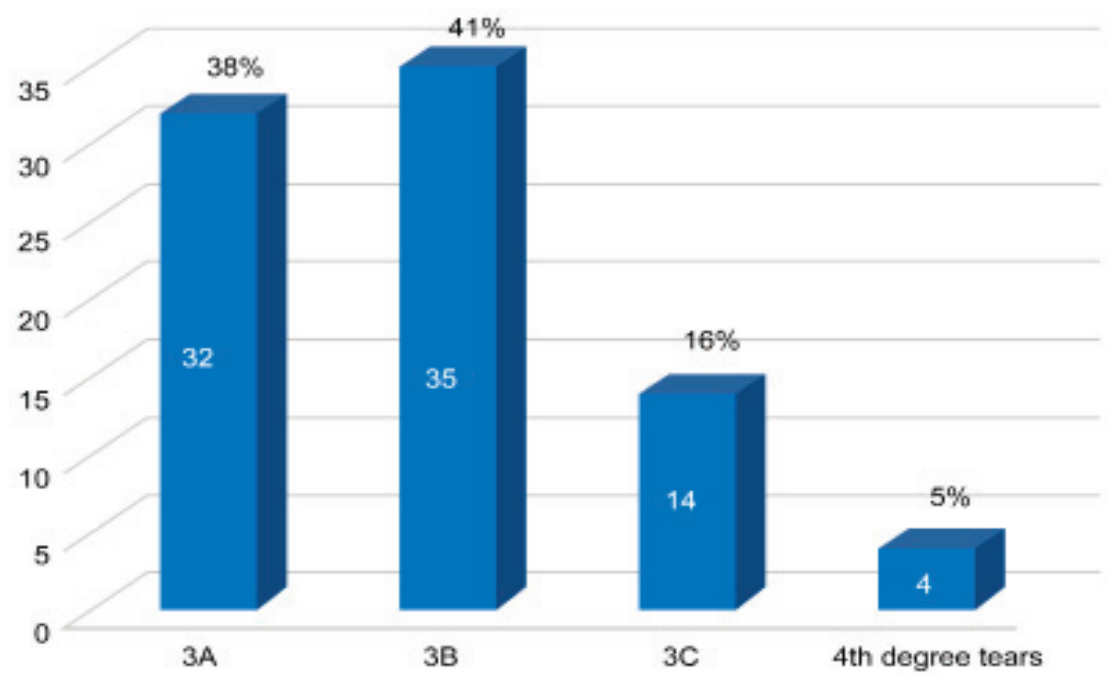

Figure 1 - Types and rates of perineal tears.

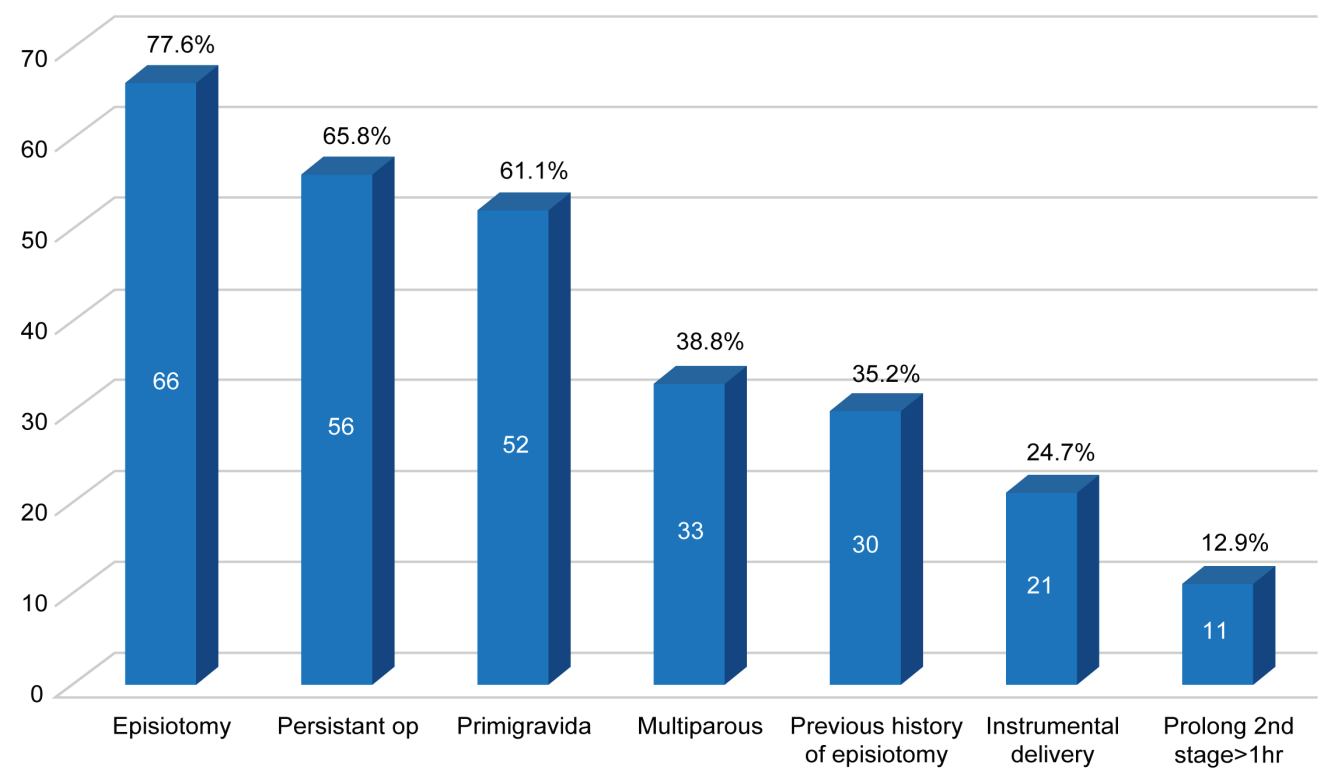

Figure $\mathbf{2}$ - Types and rates of predisposing factors.

established factors for OASIS. Similar results have been reported. ${ }^{17,21-23}$ Another well-established risk factor for OASIS is prolonged second stage of labor, which occurred in $12 \%$ of the women in this study. This was a lower rate compared to that of other studies. ${ }^{17,21,22}$

Induction of labor, weight at birth, post maturity, head circumference, and shoulder dystocia have been reported as risk factors for OASIS, ${ }^{20,21}$ but this study failed to confirm their significance.
Study limitations. This is a retrospective and single center, and this study may arise perineal tears in the southwest region of KSA, that can be a basis for future studies in the region.

In conclusion, the low incidence of OASIS in our hospital is the result of proactive manual protection of the perineum and valid indications for performing an episiotomy. Serious injuries to the birth canal are difficult to predict. An adequate examination of the 
birth canal is necessary to detect early the potential for third- and fourth-degree perineal injuries. The consequences of perineal injuries on the well-being of young mothers can be serious and can affect the social and sexual aspects of their life. Surgical treatment and postoperative care ensure optimal results and prevent long-term complications such as fistula or fecal incontinence. Clinicians must be aware of the devastating consequences of untreated injuries.

Acknowledgment. I thank Dr. Waleed Houshimi, a consulting gynecologist, for his invaluable help and advice during this study, Mr. Vher Crisostomo for secretarial assistance and the English editing company (editage.com) for revising the manuscript.

\section{References}

1. Thach T. Methods of repair for obstetric anal sphincter injury: WHO Reproductive Health Library commentary. Geneva: World Health Organization; 2006.

2. Koelbl H, Nitti V, Baessler K, Salvatore S, Sultan A, Yamaguchi O. Pathophysiology of urinary incontinence, faecal incontinence and pelvic organ prolapse. In: Abrams P, Cardozo L, Khoury S, Wein A, editors. Incontinence: 4th International Consultation on Incontinence, Paris, France, July 5-8, 2008. Paris: Health Publication, Ltd.; 2009. p. 255-330.

3. Fernando R, Williams A, Adams E. The Management of Thirdand Fourth-degree Perineal Tears (Green-top Guideline No 29). London: RCOG; 2015.

4. Haylen BT, De Ridder D, Freeman RM, Swift SE, Berghmans $\mathrm{B}$, Lee J, et al. An International Urogynecological Association (IUGA)/International Continence Society (ICS) joint report on the terminology for female pelvic floor dysfunction. Neurourol Urodyn 2010; 29: 4-20.

5. Crawford LA, Quint EH, Pearl ML, DeLancey J. Incontinence following rupture of the anal sphincter during delivery. Obstet Gynecol 1993; 82: 527-531.

6. Handa VL, Danielsen BH, Gilbert WM. Obstetric anal sphincter lacerations. Obstet Gynecol 2001; 98: 225-230.

7. Baghestan E, Irgens LM, Børdahl PE, Rasmussen S. Trends in risk factors for obstetric anal sphincter injuries in Norway. Obstet Gynecol 2010; 116: 25-34.

8. McPherson KC, Beggs AD, Sultan AH, Thakar R. Can the risk of obstetric anal sphincter injuries (OASIs) be predicted using a risk-scoring system? BMC Res Notes 2014; 7: 471.

9. Rognant S, Benoist G, Creveuil C, Dreyfus M. Obstetrical situations with a high risk of anal sphincter laceration in vacuum-assisted deliveries. Acta Obstet Gynecol Scand 2012; 91: 862-868.
10. World Health Organization. International Classification of Diseases (ICD). Vienna: WHO; 2015.

11. Jandér C, Lyrenäs $S$. Third and fourth degree perineal tears: predictor factors in a referral hospital. Acta Obstet Gynecol Scand 2001; 80: 229-234.

12. Rizvi RM, Chaudhury N. Practices regarding diagnosis and management of third and fourth degree perineal tears. J Pak Med Assoc 2008; 58: 244-247.

13. Samuelsson E, Ladfors L, Wennerholm U, Gåreberg B, Nyberg $\mathrm{K}$, Hagberg H. Anal sphincter tears: prospective study of obstetric risk factors. BJOG 2000; 107: 926-931.

14. Jangö H, Langhoff-Roos J, Rosthøj S, Sakse A. Modifiable risk factors of obstetric anal sphincter injury in primiparous women: a population-based cohort study. Am J Obstet Gynecol 2014; 210: 59. e1-e6.

15. Amorim MM, Franca-Neto AH, Leal NV, Melo FO, Maia SB, Alves JN. Is it possible to never perform episiotomy during vaginal delivery? Obstet Gynecol 2014; 123: 38S.

16. Murphy D, Macleod M, Bahl R, Goyder K, Howarth L, Strachan B. A randomised controlled trial of routine versus restrictive use of episiotomy at operative vaginal delivery: a multicentre pilot study. BJOG 2008; 115: 1695-1703.

17. Groutz A, Hasson J, Wengier A, Gold R, Skornick-Rapaport A, Lessing JB, et al. Third- and fourth-degree perineal tears: prevalence and risk factors in the third millennium. Am J Obstet Gynecol 2011; 204: e1-e4.

18. Revicky V, Nirmal D, Mukhopadhyay S, Morris EP, Nieto JJ. Could a mediolateral episiotomy prevent obstetric anal sphincter injury? Eur J Obstet Gynecol Reprod Biol 2010; 150: 142-146.

19. Elisabeth Hals,Pal Oian,Tiina Pirhonen,Mika Gissler,Sssel Hjelle,Elisabeth Berge Nilsen etal.Amulticenter interventional program to reduce the incidence of anal sphincter tear. Obestet Gynecol 2010; 116: 4.

20. Stedenfeldt M, Pirhonen J, Blix E, Wilsgaard T, Vonen B, Øian P. Episiotomy characteristics and risks for obstetric anal sphincter injuries: a case-control study. BJOG 2012; 119: 724-730

21. Al-Ghamdi T, Al-Thaydi A, Chamsi AT, Mardawi E. Incidence and risk factors for development of third and fourth degree perineal tears: a four year experience in a single Saudi center. J Women's Health Care 2018; 7. DOI:10.4172/21670420.1000423

22. Sultan AH, Kamm M, Hudson C, Bartram C. Third degree obstetric anal sphincter tears: risk factors and outcome of primary repair. BMJ 1994; 308: 887-891.

23. de Leeuw JW, Struijk P, Vierhout M, Wallenburg H. Risk factors for third degree perineal ruptures during delivery. BJOG 2001; 108: 383-387. 